\title{
Pengembangan Modul Matematika Bernuansa Keislaman melalui Metode Scaffolding
}

\section{Fitri Mulianda ${ }^{1^{*}}$, Dian Anggraini ${ }^{2}$}

'Pendidikan Matematika, UIN Raden Intan Lampung, Bandar Lampung, Indonesia; *fitri.10mulianda@gmail.com

2Dian Anggraini, Institut Teknologi Sumatra, Lampung Selatan, Indonesia; dian.anggraini@at.itera.ac.id

Abstrak. Tujuan penelitian ini adalah untuk mengetahui pengembangan, kelayakan, kemenarikan serta kefektifan produk yang dikembangkan pada SMA Al-Kautsar Bandar Lampung dan MAN 2 Bandar Lampung. Prosedur yang digunakan adalah resert and development dengan metode penelitian dan pengembangan 4-D yang digagas oleh Thiagarajan. Instrument pengumpulan data dilakukan dengan cara penyebaran angket kelayakan kepada ahli materi, ahli media, ahli agama dan praktisi pendidikan, penyebaran angket kemenarikan kepada peserta didik dalam uji coba skala kecil dan ujicoba skala besar serta pemberian soal pre-post test dalam ujicoba efektivitas yang menggunakan perhitungan N-Gain. Diperoleh hasil kelayakan sebesar 3,6 oleh ahli materi, 3,5 oleh ahli media, dan 3,7 oleh ahli agama, maka diperoleh rata-rata sebesar 3,6 dengan kriteria "sangat layak". Respon peserta didik menyatakan bahwa modul sangat menarik dengan diperoleh nilai rata-rata dari kedua sekolah sebesar 3,47 dengan kriteria "sangat menarik" pada uji coba skala kecil dan 3,33 dengan kriteria "sangat menarik" pada uji coba skala besar. Hasil uji efektivitas diperoleh nilai sebesar 0,77 pada SMA Al-Kautsar Bandar Lampung dan diperoleh nilai sebesar 0,72 pada MAN 2 Bandar Lampung. Berdasarkan rentang kriteria nilai Gain yaitu $\geq 0,7$, maka modul matematika SMA bernuansa keislaman berbasis scaffolding pada materi limit fungsi aljabar dikategorika efektif dengan klasifikasi tinggi.

Kata Kunci: Pengembangan, Modul, Islami, Scaffolding.

Abstract. The purpose of this research is in order to know the development, appropriateness, attractiveness and effectiveness of product developed in AlKautsar Bandar Lampung senior high school and MAN 2 Bandar Lampung. The procedure used is resert and development with research method and the 4-D development initiated by Thiagarajan. The data collection instrument conducted by spreading appropriateness questionnaires to the subject expert, media expert, religion expert, and education practitioner, deployment of 
appropriateness questionnaires to students in small scale trial and big scale trial and giving pre post test in effectiveness trial using N-Gain calculation. Obtained effectiveness result in the amount of 3,6 from subject expert, 3,5 from media expert, and 3,7 from religion expert, then its average is 3,6. It gets "very decent barometer". The students' response showed that the module is very interesting with average 3,47 from both schools with "very decent criteria" on small scale trial and 3,3 with "very decent criteria" on big scale trial. The result of effectiveness trial got 0,77 at SMA Al-Kautsar Bandar Lampung and 0,72 at MAN 2 Bandar Lampung. Based on Gain score range that is $\geq 0,7$, so mathematics module framed in nuance of Islam through scaffolding on aljabar function limit subject is categorized with high classification.

Keywords: Consists Development, Module, Islam, Scaffolding

\section{Pendahuluan}

Pendidikan merupakan suatu wadah dalam meningkatkan kemajuan bangsa. Melalui pendidikan, seseorang lebih dipandang terhormat dan dapat memiliki karir yang baik dan dapat bertingkah sesuai dengan norma-norma yang berlaku. Pendidikan berperan untuk mengembangkan dan membentuk kepribadian dan perilaku setiap individu agar menjadi manusia yang berakhlak mulia, berilmu, memiliki keterampilan serta beriman dan bertaqwa kepada Allah SWT( Fiska, Farida \& Syazali, 2016). Oleh karna itu dibutuhkan pendidikan yang mengajarkan nilai-nilai untuk membentuk kepribadian yang berilmu serta beriman dan bertaqwa yaitu pendidikan islam. Nilai-nilai islami dapat dipadukan dalam pembelajaran khususnya pada pembelajaran matematika (Mulya, Netriwati \& fraulein, 2018).

Pendidikan bernuansa keislaman atau mengandung nilai-nilai keislaman dalam pelajaran matematika di Madrasah dan Perguruan Tinggi Islam dewasa ini mulai dikembangkan, nilai-nilai keislaman inilah yang membedakan pendidikan disekolah dan perguruan tinggi umum dengan Madrasah dan Perguruan Tinggi Islam yang kental dengan nilai-nilai keislaman yang diterapkan. Bernuansa keislaman yang dimaksud disini adalah berkaitan dengan usaha memadukan keilmuan matematika secara umum dengan islam tanpa harus menghilangkan keunikan-keunikan dari kedua ilmu tersebut (Nanang Supriadi, 2015). Nuansa keislaman dalam modul matematika ini tergambar dalam desain modul dengan nuansa keislaman, ayat-ayat AlQur'an dan para ilmuan muslim sebagai motivasi dalam belajar, serta materi matematika yang dikaitkan dengan nilai-nilai keislaman tanpa mengubah standar kompetensi yang terkandung dalam kurikulum yang telah diterapkan.

Copyright $@ 2021$

Buana Matematika :

Jurnal Ilmiah Matematika dan Pendidikan Matematika 
Dalam proses pembelajaran matematika, peserta didik membutuhkan motivasi dari pendidik agar mereka mau dan mampu menyelesaikan soalsoal, serta membimbingnya sampai mereka dapat menyelesaikannya. Bimbingan yang dimaksud dapat diberikan secara lisan maupun tertulis, akan tetapi bantuan secara tertulis jauh lebih efektif, karena dapat dibaca secara berulang-ulang kapan dan dimana saja oleh peserta didik. Modul merupakan salah satu alternatif pembelajaran yang tepat bagi peserta didik karena modul akan membantu peserta didik lebih mandiri untuk menambah informasi tentang konsep yang dipelajari melalui kegiatan belajar secara sistematis (Syarifah, Farida \& Syazali, 2016).

Modul bertujuan untuk membuat peserta didik belajar secara mandiri tanpa atau dengan bimbingan pendidik, sehingga modul paling tidak berisi tentang komponen pokok bahan ajar (Taza, Agus \& Suherman, 2018). Modul sangat baik digunakan untuk meningkatkan keterlibatan peserta didik dalam proses pembelajaran. Vygotsky menyatakan bahwa proses pembelajaran akan terjadi jika anak bekerja atau menangani tugas-tugas yang belum dipelajari namun tugas-tugas itu masih berada dalam jangkauan kemampaunnya atau tugas tersebut berada dalam zone of proximal development. zone of proximal development adalah perkembangan sedikit di atas perkembangan seseorang saat ini (Trianto, 2014). Dengan demikian, penulis memberikan alternatif yaitu menggunakan metode yang mana dalam proses pembelajarannya memberikan bantuan peserta didik bantuan secara bertahap agar peserta didik mau dan mampu menyelesaikan soal-soal matematika, sehingga peserta didik lebih memahami materi yang telah disampaikan oleh pendidik. Metode tersebut adalah metode scaffolding.

Scaffolding adalah memberikan sejumlah bantuan kepada peserta didik selama tahap-tahap awal pembelajaran kemudian anak tersebut mengambil alih tanggung jawab yang semakin besar segera setelah ia mampu melakukannya. Bantuan tersebut dapat berupa petunjuk, peringatan, motivasi, dorongan, menguraikan masalah dalam langkah-langkah pemecahan, memberikan contoh, atau yang lainnya sehingga memingkinkan peserta didik tumbuh mandiri (Trianto, 2014). Scaffolding dalam penelitian ini akan diterapkan dalam isi modul.

Penelitian mengenai modul dilakukan oleh Lidya Alimah Fitri, Eko Setyadi Kurniawan dan Nur Ngazizah dengan hasil penelitian menyatakan bahwa kualitas modul yang dikembangkan berkatagori baik dan layak digunakan dalam pembelajaran fisika (Lidya, Fitri \& Eko, 2013).. Perbedaan antara

Copyright $@ 2021$

Buana Matematika :

Jurnal Ilmiah Matematika dan Pendidikan Matematika 
penelitian oleh Lidy Alimah Fitri dkk dengan penelitian yang akan dilakukan adalah dalam penelitian ini modul matematika yang dikembangkan pada mata pelajaran fisika dengan pada penelitian yang akan dilakukan modul yang dikembangkan adalah pada mata pelajaran matematika. Selanjutnya, Penelitian mengenai modul bernuansa keislaman yang dilakukan oleh Mulya Diana, modul yang dikembangkan mendapat respon dari peserta didik dengan skor rata-rata 89,0061\% dengan kriteria sangat menarik dan respon pendidik dengan skor rata-rata 85,490196\% dengan kriteria sangat layak (Mulya, Netriwati \& Fraulein, 2016). Perbedaan antara penelitian ini dengan penelitian yang akan dilakukan oleh peneliti adalah dalam penelitian ini modul yang dikembangkan berbasis inkuiri sedangkan modul yang akan dikembangkan adalah berbasis scaffolding. penelitian mengenai scaffolding juga dilakukan oleh Nicke Septriani, Irwan dan Meira dengan judul penelitian Pengaruh Penerapan Pendekatan Scaffolding terhadap Kemampuan Pemahaman Konsep Matematika Siswa Kelas VIII SMP Pertiwi 2 Padang. Hasil penelitian tersebut menyatakan bahwa kemampuan pemahaman siswa dengan pendekatan scaffolding lebih baik daripada kemampuan pemahaman konsep matematika siswa dengan pembelajaran secara konvensional (Nicke, Irwa \& Meira, 2014). Perbedaan antara penelitian tersebut dengan penelitian yang akan dilakukan adalah dalam penelitian tersebut peneliti menggunakan pembelajaran berbasis scaffolding untuk melihat pengaruhnya terhadap Kemampuan Pemahaman Konsep Matematika Siswa, sedangkan penelitian yang akan dikembangkan, scaffolding diterapkan dalam isi modul.

Penggunaan modul dapat menambah pengetahuan bagi peserta didik dalam proses pembelajaran. Sehingga perlu adanya pengembangan modul bernuansa keislaman berbasis scaffolding. Oleh karena itu, peneliti tertarik untuk malakukan penelitian yang berjudul Pengembangan Modul Matematika SMA Bernuansa Keislaman Berbasis Scaffolding pada Materi Limit Fungsi Aljabar.

\section{Metode}

Penelitian ini menggunakan metode penelitian dan pengembangan atau Researt and Development (RED). Sugiono berpendapat bahwa penelitian dan pengembangan atau Researt and Development (RED) adalah metode penelitian untuk menghasilkan suatu produk tertentu dan mengkaji keefektifan dari produk tersebut (Sugiono, 2017). Produk yang dihasilkan pada penelitian ini adalah modul matematika bernuansa keislaman melalui metode scaffolding. 
Model penelitian yang digunakan pada penelitian ini adalah 4-D atau singkatan dari define, design, develop dan disseminate yang dikembangkan oleh Thiagarajan (2014). Model 4-D dipilih dalam penelitian ini karna model ini lebih sistematis dengan hanya menggunakan empat tahapan utama dan sudah banyak digunakan dalam penelitian pengembangan model pembelajaran.

Instrument pengumpulan data yang digunakan adalah lembar validasi, lembar angket serta soal pretest dan posttest. Lembar validasi dan lembar angket yang digunakan terdiri dari 4 jawaban, sehingga skor penilaian total dari hasil instrumen uji coba dapat dicari dengan menggunakan rumus sebagai berikut:

dengan :

$$
\mathrm{x}_{\mathrm{i}}=\frac{\text { Jumlah skor }}{\text { Jumlah skor maksimal }} \times 4
$$

Katerangan :

$\overline{\mathrm{x}}=$ Rata-rata akhir

$\mathrm{x}_{\mathrm{i}}=$ Nilai uji operasional angket setiap peserta didik

$\mathrm{n}=$ banyaknya peserta didik yang mengisi angket

Hasil dari skor penilaian dari para ahli dicari rata-ratanya dan dikonversikan untuk menentukan kelayakan produk yang dikembangkan. Kriteria kelayakan analisis rata-rata dapat dilihat pada Tabel 1.

Tabel 1.Kriteria Validasi (dimodifikasi)

\begin{tabular}{ccc}
\hline Skor Kualitas & Kriteria kelayakan & Keterangan \\
\hline $1,00<\bar{x} \leq 1,76$ & Tidak Valid & Revisi Total \\
$1,76<\bar{x} \leq 2,51$ & Kurang Valid & Revisi Sebagian \& pengkajian \\
& & ulang materi \\
$2,51<\bar{x} \leq 3,26$ & Cukup Valid & Revisi Sebagian \\
$3,26<\bar{x} \leq 4,00$ & Valid & Tidak Revisi \\
\hline
\end{tabular}

Hasil skor penilaian dari masing-masing peserta didik dicari rata-rata dan dikonversikan untuk menentukan kemenarikan produk. Penkorversian skor penilaian ini dapat dilihat pada Tabel 2.

Tabel 2. Kriteria Uji kKemenarikan (modifikasi)

\begin{tabular}{cc}
\hline Skor Kualitas & Kriteria Kelayakan \\
\hline $1,00<\bar{x} \leq 1,76$ & Sangat Kurang Menarik
\end{tabular}

Copyright (C) 2021

Ouana Matematika :

Jurnal Ilmiah Matematika dan Pendidikan Matematika 
Jurnal Ilmiah Matematika dan Pendidikan Matematika

Vol. 11 No. 1 (2021)

\begin{tabular}{cc}
\hline Skor Kualitas & Kriteria Kelayakan \\
\hline $1,76<\bar{x} \leq 2,51$ & Kurang Menarik \\
$2,51<\bar{x} \leq 3,26$ & Menarik \\
$3,26<\bar{x} \leq 4,00$ & Sangat Menarik \\
\hline
\end{tabular}

\section{Hasil dan Pembahasan}

Penelitian ini menghasilkan produk berupa modul matematika bernuansa islami melalui metode scaffolding. Materi yang digunakan adalah limit fungsi aljabar yang dikembangkan berdasarkan metode scaffolding. Nantinya modul yang dihasilkan diharapkan mampu menjadi reverensi belajar bagi peserta didik agar peserta didik lebih mandiri dalam pembelajaran matematika khususnya pada materi limit fungsi aljabar. Model penelitian yang digunakan dalam penelitian ini adalah 4-D dari Thiagarajan yang mencangkup empat tahapan utama yaitu define (pendefinisian), design (perancangan), develop (pengembangan) dan disseminate (penyebaran). Secara konseptual prosedur penelitian 4-D antara lain:

a. Define (pendefinisian)

1. Analisis Front-End (Front-End Analysis)

Front-end analysis adalah analisis kebutuhan yang mengacu pada keadaan lapangan dengan tujuan untuk mengetahui apakah produk yang akan dikembangkan dibutuhkan serta perlu atau tidaknya produk dikembangkan.

2. Analisis Konsep (Concept Analysis)

mengidentifikasi bagian-bagian utama pada materi limit fungsi yang berpedoman pada kurikulum 2013 (K13), pada modul yang dikembangkan peneliti menyusun materi limit fungsi aljabar secara sistematis relevan dalam tiga bab diantaranya pengertian limit, operasi pada limit dan teorema limit.

3. Analisis Tugas (Task Analysis)

menganalisis tugas-tugas pokok yang harus dikuasai oleh peserta didik agar dapat mencapai kompetensi minimal. Setelah analisis tugas dilakukan maka diperoleh gambaran contoh soal dan latihan perbab materi limit fungsi aljabar yang menggunakan metode scaffolding.

4. Spesifikasi Tujuan Intruksional (Specifying Intructional Objectives)

Copyright (C) 2021

Buana Matematika :

Jurnal Ilmiah Matematika dan Pendidikan Matematika 
merumuskan tujuan dengan cara merangkum hasil dari analisis frontend, analisis konsep dan analisis tugas yang bertujuan untuk menentukan perilaku objek penelitian.

\section{b. Design (Perancangan)}

1. Penyususnan Tes Acuan Patokan (Contructing criterion-Referenced Test) Modul matematika SMA bernuansa keislaman berbasis scaffolding dipilih sebagai bahan ajar yang dikembangkan, hal ini bertujuan agar memudahkan dan membantu peserta didik lebih mandiri dalam proses pembelajaran.

2. Pemilihan Format (Format Selection)

Penyusunan desain produk pada modul ini memiliki beberapa langkahlangkah diantaranya yaitu menyesuaikan kompetensi inti dan kompetensi dasar serta silabus yang didasarkan pada kurikulum 2013 (K13).

3. Rancangan Awal (Intial Design)

Rancangan awal produk pengemangan modul diantaranya terdiri dari cover depan dan cover belakang, halaman tim pengembang modul, kata pengantar, daftar isi, pendahuluan, standar isi dan peta konsep. Sedangkan isi modul terdiri dari kegiatan pembelajaran, ayat-ayat yang berhubungan dengan materi limit, tokoh-tokoh ilmuan muslim sebagai motivasi bagi peserta didik, zone of proximal development untuk melihat perkembangan peserta didik serta scaffolding atau bantuan yang memudahkan peserta didik dalam memahami materi dan pengerjaan soal-soal.

\section{c. Develop (Pengembangan)}

Kegiatan yang dilakukan pada tahap ini adalah validasi pada para ahli (ahli materi, ahli media, ahli agama dan praktisi pendidikan), validasi dilakukan secara dua tahap yaitu tahap satu dan tahap dua untuk memperoleh kelayakan modul. Hasil penilaian dari para ahli dapat dilihat pada Tabel 3. 
Tabel 3 Hasil Penilaian Produk Oleh Para Ahli

\begin{tabular}{ccccccc}
\hline Produk & $\begin{array}{c}\text { Ahli } \\
\text { Materi }\end{array}$ & $\begin{array}{c}\text { Ahli } \\
\text { Media }\end{array}$ & $\begin{array}{c}\text { Ahli } \\
\text { Agama }\end{array}$ & Guru & Rata-rata & Kriteria \\
\hline Modul & 3,6 & 3,4 & 3,7 & 3,6 & 3,57 & $\begin{array}{c}\text { Sangat } \\
\text { Layak }\end{array}$ \\
\hline
\end{tabular}

Setelah dinyatakan layak, modul diujicoba pada ujicoba kelompok kecil dan ujicoba kelompok besar untuk menilai kemenarikan modul. Hasil penilaian kelompok kecil dan kelompok besar dapat dilihat pada Gambar 1.

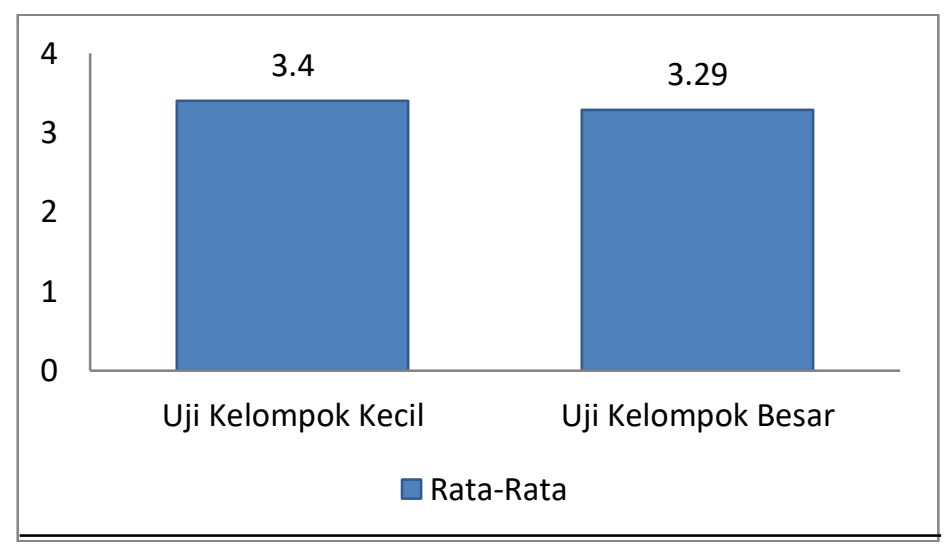

Gambar 1. Hasil Penilaian Ujicoba Kelompok kecil dan Kelompok Besar

\section{d. Dessiminate (Penyebaran)}

Penyebaran dilakukan kepada pendidik dalam belum cetak maupun Softfile Modul sedangkan penyebaran masal pada peserta didik dilakukan dengan mengirimkan softfile modul melalui grup pada aplikasi whatsapp.

\section{Simpulan}

Simpulan dari penelitian ini yaitu modul matematika bernuansa keislaman melalui metode scaffolding yang telah dikembangkan mem peroleh nilai kelayakan dari para ahli sebesar 3,57 dengan kriteria sangat layak dan memperoleh respon kemenarikan dari uji coba kelompok kecil 3,4 dengan kriteria sangat menarik dan respon pada uji coba kelompok besar 3,29 dengan kriteria sangat menarik. 
Saran yang dapat diajukan adalah modul matematika bernuansa keislaman melalui metode scaffolding materi yang disajikan hanya pada limit fungsi aljabar sehingga untuk pengembangan modul berikutnya dapat dikembangan modul matematika bernuansa keislaman melalui metode scaffolding pada materi yang lebih luas.

\section{Daftar Pustaka}

Rizkiah, A. W. (2018). LKPD Discussion Activity Terintegrasi Keislaman dengan Pendekatan Pictorial Riddle pada Materi Pecahan. Desimal .

AGENG, S. (2018). PENGEMBANGAN MODUL BILINGUAL BERGAMBAR BERBASIS QUANTUM LEARNING PADA MATERI PELUANG. DESIMAL: JURNAL MATEMATIKA

Alimah, F. L. (2013). Pengembangan Modul Fisika pada Pokok Bahasan Listrik Dinamis Berbasis Domain Pengetahuan Siauns Untuk Mengoptimalkan Minds-On Siswa SMA Negri 2 Perworejo Kelas X Tahun Pelajaran 2020/2013. Radiasi: Jurnal Berskala Pendidikan Fisika .

Amri, S., \& Ahmadi, A. K. (2010). konstruksi pengembangan pembelajaran pengaruhnya terhadap mekanisme dan praktik kurikulum. Jakarta: prestasi Pustakarya.

Anggoro, B. S. (2015). Pengembangan Modul Matematika dengan Strategi Problem Solvin untuk Mengukur Tingkat Kemampuan Berpikir Kreatif Matematis Siswa. Al-Jabar.

Annisah, K. (2015). Mengenalkan Matematika Terintegrasi Islam Kepada Anak Sejak Dini. Suska Journal Of Mathematics Education

Arlitasari, S., Pujayanto, P., \& Budiharti, R. (2013). pengembangan bahan ajar IPA terpadu berbasis saling temas dengan tema biomassa sumber energi alternatif terbarukan. jurnal pendidikan fisika .

Astika, F. F. (2014). Pengembangan Modul pada Materi Matriks dengan Pendekatan PMRI untuk Siswa Kelas X SMK. Skripsi .

Chairani, Z. (2015). Scaffolding dalam Pembelajaran Matematika. Math Didactic: Jurnal Pendidikan Matematika .

Copyright (C) 2021

Buana Matematika :

Jurnal Ilmiah Matematika dan Pendidikan Matematika 
Faniie, R. D., \& Rohati. (2014). pengembangan lembar kerja siswa (LKS) Berbasis POE pada materi program linear kelas XII SMA. Jurnal sains dan matematika universitas jambi .

Hamdani. (2010). Strategi Belajar Mengajar. Bandung: CV Pustaka Setia.

Indrawati. (2017). Pengaruh Metode Scaffolding Berbasis Konstruktivisme Terhadap Hasil Belajar Matematika. Journal Of Medives: Journal Of mathematics Education IKIP Veteran Semarang .

Jannah, A. I. (2017). Pengembangan Bahan Ajar pada Bahasan Himpunan dengn Pendekatan Prolem Solving untuk Siswa SMP Kelas VII. Jurnal Pendidikan Matematika .

Kurniati, A. (2016). Pengembangan Modul Metematika Berbasis Kontekstual Terintegrasi Ilmu Keislaman. Al-Khawarizmi: Jurnal Pendidikan Matematika DAn Ilmu Pengetahuan Alam .

Lubis, M. S., Syahrul, R., \& Novi, J. (2014). Pengembangan Modul Pembelajarn Bahasa Indonesia Berbantuan Peta Pikiran Pada Materi Menulis Makalah Siswa Kelas XI SMA/MA. Bahasa Sastra dan Pembelajaran .

Mamin, R. (2013). Penerapan Metode Pembelajaran Scaffolding pada Pokok Bahasan Sistem Periodik Unsur. Chemica .

Mardiansyah, Y. (2013). Pembuatan Modul Matematika Berbasis TIK untuk Mengintegrasikan Nilai Pendidikan Karakter dalam Pembelajaran Siswa SMAN 10 Padang Kelas X Semester 1. Pllar Of Physics Education .

Marsigit. (2010). Matematika SMA Kelas XII. Jakarta: Quadra.

Mutia, D. (2017). pengembangan modul metematika menggunakan model Thiagarajan untuk meningkatkan kemampuan pemecahan masalah melalui pendekatan pembelajaran matematika realistic di MTs pesantren daar uluum Kisaran.

Narbuko, C., \& Achmadi, H. A. (2009). Metodelogi Penelitian. Jakarta: Bumi Aksara.

Copyright (C) 2021

Buana Matematika :

Jurnal Ilmiah Matematika dan Pendidikan Matematika 
Rizkiah, A. W. (2018). LKPD Discussion Activity Terintegrasi Keislaman dengan Pendekatan Pictorial Riddle pada Materi Pecahan. Desimal .

Salafudin. (2015). pembelajaran matematika yang bermuatan nilai islam. urnal penellitian .

Sari, F. K., Farida, \& Syazali, M. (2016). Pengembangan Media Pembelajaran (Modul) Berbantuan Geogebra Pokok Bahasan Turunan. Al-Jabar .

Septora, R. (2017). pengembangan modul dengan menggunakan pendekatan saintifik pada kelas $\mathrm{X}$ sekolah menengh atas. jurnal lentera pendidikan pusat penelitian LPPM UM Metro .

Septriani, N. (2014). pengaruh penerapan pendekatan scaffolding terhadap kemampuan pemahammatika siswa kelas VIII SMP Pertiwi 2 Padangan konsep mat. jurnal pendidikan matematika .

Sugiyono. (2017). metode penelitian kuantitatif, kualititaf dan RED. Bandung: alfabeta.

Sukino. (2017). matematika untuk SMA/MA kelas XI Semester 1. Jakarta: Erlangga.

Supriadi, N. (2015). mengembangkan kemampuan koneksi matematis melalui buku ajar elektronik interaktif yang terintegrasi n ilai-nilai keislaman. Alabar: jurnal pendidikan matematika .

Sutarmi, N. W., Suharsono, N., \& Warpala, I. W. (2013). pengaruh pembelajaran scaffolding terhadap keterampilan menulis teks recount berbahasa inggris dan kreativitas siswa kelas VIII SMP Negri 3 Manggis. Jurnal teknologi pembelajaran indonesia .

Syahrifah, S. (2017). pengemangan lembar kerja peserta didik (LKPD) berorientasi nilai-nilai agama islam melalui pendekatan inquiry terbimbing materi trigonometri. PhD Thesis UIN raden intan Lampung .

Syahrir, \& Susilawati. (2015). pengembangan modul pembelajaran matematika siswa SMP. jurnal ilmiah mandala education (JIME) .

Copyright (C) 2021

Buana Matematika :

Jurnal Ilmiah Matematika dan Pendidikan Matematika 
Trianto. (2014). model pembelajaran terpadu konsep, strategi dan implementasi dalam kurikulum tingkat satuan pendidikan. Jakarta: Bumi Aksara.

Utami, T. N., Agus, J., \& Suherman. (2018). pengembangan modl matematika dengan pendekatan science, Technology, engineering, and mathematics (STEM) pada materi segiempat. Desimal: Jurnal Matematika .

Wena, M. (2012). strategi pembelajaran inovatif kontemporer. Jakarta: Bumi Aksara. 